\title{
Effect of Some Acaricide Treatments on Some Biological Aspects of the Two-Spotted Spider Mite Tetranychus urticae Koch and its Predator Phytoseiulus persimilis Athias-Henriot
}

\author{
Alyaa A. Tawfik* and L. R. A. El Gohary ${ }^{* *}$ \\ *Plant Protection Research Institute, Agricultural Research Center, Dokki, Giza, Egypt \\ *** Department of pesticide, Faculty of Agriculture, Mansoura University, Mansoura, Egypt
}

\begin{abstract}
The present study was conducted to evaluate the effect of the field recommended rate of five commercial acaricides namely Ethion, Fenpyroximate, Etoxazole, Chlorfenapyr and Abamectin on some biological aspects of the two-spotted spider mite Tetranychus urticae Koch (Acari: Tetranychidae) and its predator Phytoseiulus persimilis Athias- Henriot. Both predator and prey were proceeded under laboratory conditions at $28 \pm 2{ }^{\circ} \mathrm{C}$. Results showed significant differences among the five developmental treatments and control in the duration of male and female of P. persimilis and T. urticae after treating eggs with certain acaricides.The results also revealed that Abamectin was the most effective acaricide on growth index, developmental rate and mean survival percentages of immature stages of $T$. urticae female. On the other hand, Chlorfenapyr was the most effective acaricide on growth index and mean survival percentages of $P$. persimilis immature stages, while Abamectin was the most effective of female, acaricide on its developmental rate.
\end{abstract}

Key Words: Acaricides, Biology, Tetranychus urticae, Phytoseiulus persimilis.

\section{INTRODUCTION}

The two-spotted spider mite Tetranychus urticae Koch and its predator Phytoseiulus persimilis Athias- Henriot are widely spread throughout the Mediterranean area. T. urticae is considered one of the most important pests. It is responsible for yield losses in many horticultural, ornamental and agricultural systems mainly annual crops and vegetables (Helle \&Sabelis, 1985). The predatory mites, $P$. persimilis is the most effective biological control agent for control of the two-spotted spider mite, T. urticae. This agent has been applied in several greenhouse vegetable crops (Lee, et al., 2002; Malezieux et al., 1992). Predator-prey interactions in crops may be affected by pesticides used to control other pests, and thus knowledge of pesticides side-effects is essential when managing spider mite populations following integrated pest management (Duso et al., 2008). Pesticides and their residues often have direct effects on spider mites, including mortality, decreased longevity, and reduced or increased fecundity (van de Vrie et al., 1972). Therefore, the objective of this study was to evaluate the effect of five acaricides on $T$. urticae and its natural enemies used in integrated pest management programmes, in particular P. persimilis.

\section{MATERIALS AND METHODS}

\section{Rearing mites}

$P$. persimilis and $T$. urticae were collected from unsprayed castor bean plants and reared at $28 \pm 2{ }^{\circ} \mathrm{C}$ and $60 \pm 5 \% \mathrm{RH}$.

\section{Screening of acaricides}

The experiment was performed on mite eggs using the leaf dip method (Castagnoli et al., 2005). Mite females were left on castor bean leaves to oviposit for $24 \mathrm{~h}$, then removed. The leaves with eggs were dipped in the test solution for 30 seconds, then placed upside down on a wet cotton pad. Four discs,with 10 eggs each of T. urticae and four discs, with 5 eggs each of $P$. persimilis, were dipped in each concentration of the tested acaricides. Hatched eggs were evaluated for five successive days of acaricides application. Thereafter, Twenty of each $T$. urticae and $P$. persimilis hatched larvae were reared singly on leaf discs up to the adulthood. Developmental periods of the different stages were recorded. Each disc of the phytoseiid mite was supplied by $20 \mathrm{~T}$. urticae larvae the consumed larvae were recorded and replaced daily by new ones. The developmental time (life cycle) and developmental rate (1/developmental time) of immature stages, survival from eggs to adult eclosion and growth index [mean of adult emergence\% / average of immature stages (life cycle)] were recorded. Developmental time for egg , protonymph and deutonymph as well as total immature stages were used to calculate developmental rates regressed against pesticide treatments (Omkar and James, 2004). All tests were conducted under laboratory conditions of $28 \pm 2{ }^{\circ} \mathrm{C}$ and $60 \pm 5 \%$ R.H.

\section{Tested acaricides}

Five acaricides were screened for their widespread use on vegetables and these are 
a. Ethion $\quad\left(\right.$ Endo $^{\circledR} \quad 50 \% \quad$ EC $) \quad$ IRAC $1 B$ organophosphate

Chemical name $S, S^{\prime}$-methylene $\operatorname{bis}(O, O$-diethyl $)$ phosphorodithioate

b. Fenpyroximate (Ortus super $^{\circledR} \quad 5 \%$ EC) IRAC 21; METI

Chemical name 1,1-dimethylethyl (E)-4-[[][(1,3dimethyl-5-phenoxy-1 $H$-pyrazol-4-yl)methylene] amino]oxy]methyl]benzoate

c. Etoxazole (Baroque ${ }^{\circledR} 10 \%$ SC) IRAC 10B; mite growth inhibitor

Chemical name 2-(2,6-difluorophenyl)-4-[4-(1,1dimethylethyl)-2-ethoxyphenyl]-4,5-

dihydrooxazole

d. Chlorfenapyr $\quad$ (Challenger $^{\circledR} \quad 36 \%$ SC) IRAC 13; arylpyrrole

Chemical name 4-bromo-2-(4-chlorophenyl)-1(ethoxymethyl)-5-(trifluoromethyl)-1 $H$-pyrrole3-carbonitrile

$\begin{array}{llll}\text { e. Abamectin } & \left(\text { Vertimec }^{\circledR}\right. & 1.8 \% & \text { EC) }\end{array}$ 6; avermectin

Chemical name 5-O-demethylavermectin $\mathrm{A}_{1 \mathrm{a}}$ (i) mixture with 5-O-demethyl-25-de (1-methylpropyl) -25-(1-methylethyl)avermectin $\mathrm{A}_{1 \mathrm{a}}$ (ii)

Each acaricide was tested at the concentration suggested for field applications (Saenz-de-Cabezon, et al., 2007). Distilled water was used as a control during micro-immersion or leaf dipping.

\section{Data analysis:}

Data for developmental time of immature stages, adults, pre-oviposition, oviposition, and postoviposition periods, longevity of females and males were subjected for one way analysis of variance (ANOVA), and the means were separated using Duncan's Multiple Range Test (CoHort Software, 2004).

\section{RESULTS AND DISCUSSION}

The investigation was conducted under laboratory conditions of $28 \pm 2{ }^{\circ} \mathrm{C}, 60 \pm 5 \%$ R.H. to evaluate the different biological developmental stages of $T$. urticae and $P$. persimilis after treating eggs with different acaricides.

\section{Biological aspects Incubation period:}

Tables (1-4) showed that egg incubation periods of $T$. urticae and its predator $P$. persimilis female and male were significantly affected by the different egg acaricides treatment except for female of T. urticae after treating egg with Ethion and male of $P$. persimilis after treating egg with Fenpyroximate. Female and male incubation period of $T$. urticae durated (3.45 \& 2.95) days in control but these were $(3.55 \& 3.05),(4.10 \& 3.60),(4.85 \& 4.35)$, $(5.65 \& 5.15)$ and $(5.20 \& 4.70)$ days after egg treatment with Ethion, Fenpyroximate, Etoxazole, Chlorfenapyr and Abamectin; respectively. Female and male egg incubation period of $P$. persimilis durated $(3.55 \& 3.05)$ days in the control but were (4.10 \&4.50), (4.15 \&3.65), (5.47 \&4.97), (5.60 $\& 5.10)$ and $(5.65 \& 5.15)$ days after the same five egg acaricides treatment.

\section{Life cycle:}

Female life cycle of $T$. urticae averaged 11.75, $11.50,10.68,8.33$ and 12.50 days after the egg acaricides treatment compared with 9.95 days in the control; while the male recorded 10.35, 10.10, 10.28, 7.23 and 11.10 dayscompared with 8.55 days in the control. Thus, the male life cycle was shorter than that of female .The life cycle of femle and male of $P$. persimilis recorded the same trend.

\section{Longevity:}

Statistical analysis cleared that T. urticae adult females did not survive when the eggs were treated with Fenpyroximate, Etoxazole, Chlorfenapyr and Abamectin; but the longevity was 7.67 days with the treatment of Ethion compared with 10.89 days of females control. Male of T. urticae died with egg treatment of Etoxazole, Chlorfenapyr and Abamectin, meanwhile, the longevity was 3.00 and 3.67 days with the egg treatment of Fenpyroximate and Ethion compared with 8.55 days in the control. The same trend was noted with females of $P$. persimilis as they died just reached adult stage with the egg treatment of Etoxazole and Chlorfenapyr but it recorded 6.45, 7.00 and 3.50 days egg treated with Ethion, Fenpyroximate and Abamectin respectively compared with 12.10 days in the control $P$. persimilis males survived after reached adult stage with the five egg acaricides treatment but the longevities were less compared with the control.

\section{Life span:}

Results showed significant differences in life span of males and females of T. urticae when eggs treated with any of the aforementioned five acaricides and that of the control. The female life span durated 19.42, 11.50, 10.68, 8.33, and 12.50 days after treating eggs with Ethion, Fenpyroximate, Etoxazole, Chlorfenapyr and Abamectin; respectively, while it was 20.84 days in the control. There were no significant differences between male life span of $P$. persimilis in all treatments except for treating egg with Ethion, Fenpyroximate and control; Meanwhile, there were significant differences in female life span of $P$. persimilis 
Table (1) Developmental duration (Mean \pm S.E. in days) of Tetranychus urticae female after egg treatment with tested acaricides at $28 \pm 2{ }^{\circ} \mathrm{C}$

\begin{tabular}{|c|c|c|c|c|c|c|c|}
\hline & Treatment & Control & Ethion & Fenpyroximate & Etoxazole & Chlorfenapyr & Abamectin \\
\hline & Egg & $3.45 \pm 0.14 d$ & $3.55 \pm 0.14 d$ & $4.10 \pm 0.20 c$ & $4.85 \pm 0.14 b$ & $5.65 \pm 0.14 a$ & $5.20 \pm 0.14 b$ \\
\hline & Larva & $1.50 \pm 0.12 b c$ & $1.70 \pm 0.12 b c$ & $1.80 \pm 0.18 b$ & $1.95 \pm 0.13 a$ & $1.35 \pm 0.13 c$ & $1.90 \pm 0.18 a b$ \\
\hline matu & Protonymph & $1.95 \pm 0.16 b$ & $2.90 \pm 0.16 a$ & $2.50 \pm 0.22 a b$ & $3.05 \pm 0.16 a$ & $1.33 \pm 0.24 c$ & $2.20 \pm 0.22 b$ \\
\hline & Deutonymph & $3.05 \pm 0.15 a$ & $3.60 \pm 0.15 a$ & $3.10 \pm 0.21 a$ & $1.83 \pm 0.19 b$ & & $3.20 \pm 0.30 a$ \\
\hline Life cycle & & $9.95 \pm 0.41 b$ & $11.75 \pm 0.41 a$ & $11.50 \pm 0.58 a$ & $10.68 \pm 0.41 a b$ & $8.33 \pm 0.41 c$ & $12.50 \pm 0.41 a$ \\
\hline & Pre-oviposition & $1.67 \pm 0.17 b$ & $2.33 \pm 0.29 a b$ & ----- & ----- & ----- & ----- \\
\hline dult & Oviposition & $8.00 \pm 0.34 a$ & $3.67 \pm 0.60 \mathrm{~b}$ & ----- & ----- & ------ & ----- \\
\hline stage & Post-oviposition & $1.22 \pm 0.16 a$ & $1.67 \pm 0.27 a$ & ----- & ----- & ----- & ----- \\
\hline & Longevity & $10.89 \pm 0.33 a$ & $7.67 \pm 0.70 b$ & ----- & ----- & ----- & ----- \\
\hline life span & & $20.84 \pm 0.29 a$ & $19.42 \pm 0.61 b$ & $11.50 \pm 0.58 c$ & $10.68 \pm 0.41 c$ & $8.33 \pm 0.41 c$ & $12.50 \pm 0.41 c$ \\
\hline
\end{tabular}

Table (2) Developmental duration (Mean \pm S.E. in days) of Tetranychus urticae male after egg treatment with tested acaricides at $28 \pm 2{ }^{\circ} \mathrm{C}$.

\begin{tabular}{|c|c|c|c|c|c|c|c|}
\hline \multicolumn{2}{|c|}{ Treatment } & Control & Ethion & Fenpyroximate & Etoxazole & Chlorfenapyr & Abamectin \\
\hline \multicolumn{2}{|c|}{ Egg } & $2.95 \pm 0.11 \mathrm{c}$ & $3.05 \pm 0.11 \mathrm{~b}$ & $3.60 \pm 0.11 \mathrm{~b}$ & $4.35 \pm 0.12 \mathrm{ab}$ & $5.15 \pm 0.12 \mathrm{a}$ & $4.70 \pm 0.11 \mathrm{a}$ \\
\hline \multirow{3}{*}{$\begin{array}{l}\text { Immature } \\
\text { stages }\end{array}$} & Larva & $1.20 \pm 0.12 \mathrm{c}$ & $1.40 \pm 0.17 \mathrm{~b}$ & $1.50 \pm 0.19 \mathrm{ab}$ & $1.65 \pm 0.15 \mathrm{a}$ & $1.05 \pm 0.28 \mathrm{c}$ & $1.60 \pm 0.23 \mathrm{a}$ \\
\hline & Protonymph & $1.65 \pm 0.14 \mathrm{~b}$ & $2.60 \pm 0.14 \mathrm{a}$ & $2.20 \pm 0.14 \mathrm{ab}$ & $2.75 \pm 0.14 \mathrm{a}$ & $1.03 \pm 0.14 \mathrm{c}$ & $1.90 \pm 0.14 \mathrm{~b}$ \\
\hline & Deutonymph & $2.75 \pm 0.16 \mathrm{~b}$ & $3.30 \pm 0.16 \mathrm{a}$ & $2.80 \pm 0.22 \mathrm{~b}$ & $1.53 \pm 0.16 \mathrm{c}$ & ----- & $2.90 \pm 2.20 \mathrm{~b}$ \\
\hline Life cycle & & $8.55 \pm 0.28 \mathrm{c}$ & $10.35 \pm 0.34 \mathrm{~b}$ & $0.37 \mathrm{~b}$ & $10.28 \pm 0.32 \mathrm{ab}$ & $7.23 \pm 0.63 c$ & $11.10 \pm 0.45$ \\
\hline Longevity & & $8.55 \pm 0.36 a$ & $3.67 \pm 0.49 b$ & $3.00 \pm 0.60 b$ & ------ & ------ & ------ \\
\hline Life span & & $17.10 \pm 0.432 a$ & $14.02 \pm 0.59 b$ & $13.10 \pm 0.72 b$ & $10.28 \pm 0.32 c$ & $7.23 \pm 0.63 c$ & $11.10 \pm 0.4$ \\
\hline
\end{tabular}

Table (3) Developmental duration (Mean \pm S.E. in days) of Phytoseiulus persimilis female after egg treatment with tested acaricides at $28 \pm 2{ }^{\circ} \mathrm{C}$

\begin{tabular}{lccccccc}
\hline \multicolumn{1}{c}{ Treatment } & Control & Ethion & Fenpyroximate & Etoxazole & Chlorfenapyr & Abamectin \\
\hline \multicolumn{2}{c}{ Egg } & $3.55 \pm 0.14 c$ & $4.10 \pm 0.14 b$ & $4.15 \pm 0.14 b$ & $5.47 \pm 0.14 a$ & $5.60 \pm 0.14 a$ & $5.65 \pm 0.14 a$ \\
\hline \multirow{2}{*}{$\begin{array}{l}\text { Immature } \\
\text { stages }\end{array}$} & Larva & $1.35 \pm 0.11 b$ & $2.40 \pm 0.11 a$ & $2.50 \pm 0.11 a$ & $2.68 \pm 0.12 a$ & $2.63 \pm 0.12 a$ & $2.50 \pm 0.11 a$ \\
\cline { 2 - 8 } & Protonymph & $1.35 \pm 0.13 c$ & $2.45 \pm 0.13 a b$ & $2.5 \pm 0.14 a$ & $2.00 \pm 0.13 b$ & $2.44 \pm 0.19 a b$ & $2.78 \pm 0.19 a$ \\
\cline { 2 - 8 } Life cycle & Deutonymph & $2.40 \pm 0.12 a b$ & $1.81 \pm 0.17 b$ & $2.44 \pm 0.19 a$ & $2.30 \pm 0.15 a b$ & $2.25 \pm 0.28 a b$ & $2.50 \pm 0.23 a$ \\
\hline \multirow{3}{*}{$\begin{array}{l}\text { Adult } \\
\text { stage }\end{array}$} & $8.65 \pm 0.34 c$ & $10.76 \pm 0.34 b$ & $11.59 \pm 0.34 b$ & $12.45 \pm 0.35 \mathrm{a} b 12.92 \pm 0.34 a \mathrm{~b}$ & $13.43 \pm 0.34 a$ \\
\cline { 2 - 8 } & Pre-oviposition & $2.40 \pm 0.19 a b$ & $2.60 \pm 0.28 a$ & $3.00 \pm 0.36 a$ & ----- & ----- & $1.50 \pm 0.44 b$ \\
\cline { 2 - 8 } & Oviposition & $8.10 \pm 0.33 a$ & $2.60 \pm 0.46 b$ & $3.00 \pm 0.30 \mathrm{a} b$ & ----- & ----- & $2.00 \pm 1.04 b$ \\
\cline { 2 - 8 } & Post-oviposition & $1.60 \pm 0.21 a$ & $1.25 \pm 0.33 a$ & $1.00 \pm 0.66 a$ & ----- & ----- & ---- \\
\hline \multirow{2}{l}{ life span } & Longevity & $12.10 \pm 0.41 a$ & $6.45 \pm 0.64 b$ & $7.00 \pm 0.74 b$ & ---- & --- & $3.50 \pm 0.91 c$ \\
\hline
\end{tabular}

Table (4) Developmental duration (Mean \pm S.E. in days) of Phytoseiulus persimilis male after egg treatment with tested acaricides at $28 \pm 2{ }^{\circ} \mathrm{C}$.

\begin{tabular}{lccccccc}
\hline \multicolumn{1}{c}{ Treatment } & Control & Ethion & Fenpyroximate & Etoxazole & Chlorfenapyr & Abamectin \\
\hline \multicolumn{1}{c}{ Egg } & $3.05 \pm 0.11 \mathrm{~b}$ & $4.50 \pm 0.11 \mathrm{ab}$ & $3.65 \pm 0.11 \mathrm{~b}$ & $4.97 \pm 0.12 \mathrm{ab}$ & $5.10 \pm 0.12 \mathrm{a}$ & $5.15 \pm 0.11 \mathrm{a}$ \\
\hline \multirow{2}{*}{$\begin{array}{l}\text { Immature } \\
\text { stages }\end{array}$} & Larva & $1.05 \pm 0.12 \mathrm{c}$ & $2.10 \pm 0.17 \mathrm{~b}$ & $2.20 \pm 0.19 \mathrm{ab}$ & $2.38 \pm 0.15 \mathrm{a}$ & $2.33 \pm 0.28 \mathrm{a}$ & $2.20 \pm 0.23 \mathrm{ab}$ \\
\cline { 2 - 8 } & Protonymph & $1.05 \pm 0.14 \mathrm{c}$ & $2.15 \pm 0.14 \mathrm{a}$ & $2.20 \pm 0.14 \mathrm{a}$ & $1.70 \pm 0.14 \mathrm{~b}$ & $2.14 \pm 0.14 \mathrm{a}$ & $2.48 \pm 0.14 \mathrm{a}$ \\
\cline { 2 - 8 } & Deutonymph & $2.10 \pm 0.16 \mathrm{ab}$ & $1.51 \pm 0.16 \mathrm{c}$ & $2.14 \pm 0.22 \mathrm{a}$ & $2.00 \pm 0.16 \mathrm{~b}$ & $1.95 \pm 0.23 \mathrm{c}$ & $2.20 \pm 2.20 \mathrm{a}$ \\
\hline Life cycle & $7.25 \pm 0.28 \mathrm{c}$ & $10.26 \pm 0.34 \mathrm{~b}$ & $10.19 \pm 0.37 \mathrm{~b}$ & $11.05 \pm 0.32 \mathrm{ab}$ & $11.52 \pm 0.63 \mathrm{ab} 12.03 \pm 0.45 \mathrm{a}$ \\
\hline Longevity & $5.80 \pm 0.28 \mathrm{a}$ & $2.14 \pm 0.34 \mathrm{~b}$ & $2.33 \pm 0.37 \mathrm{~b}$ & $2.38 \pm 0.32 \mathrm{~b}$ & $1.50 \pm 0.63 \mathrm{c}$ & $1.25 \pm 0.45 \mathrm{c}$ \\
\hline Life span & $13.05 \pm 0.48 \mathrm{a}$ & $12.40 \pm 0.58 \mathrm{~b}$ & $12.52 \pm 0.62 \mathrm{~b}$ & $13.43 \pm 0.54 \mathrm{a}$ & $13.02 \pm 1.08 \mathrm{a}$ & $13.28 \pm 0.76 \mathrm{a}$ \\
\hline
\end{tabular}


Table (5) Growth index and developmental rates of $T$. urticae and $P$. persimilis females after egg treatment with acaricides at $28 \pm 2{ }^{\circ} \mathrm{C}$.

\begin{tabular}{llll}
\hline Species & \multicolumn{1}{c}{ Treatment } & Growth index & Developmental rate \\
\hline \multirow{5}{*}{ T. urticae } & Control & 10.05 & 0.101 \\
\cline { 2 - 4 } & Ethion & 7.51 & 0.085 \\
\cline { 2 - 4 } & Fenpyroximate & 7.04 & 0.087 \\
\cline { 2 - 4 } & Etoxazole & 7.49 & 0.094 \\
\cline { 2 - 4 } & Chlorfenapyr & 7.00 & 0.120 \\
\cline { 2 - 4 } & Abamectin & 4.54 & 0.080 \\
\hline \multirow{5}{*}{ P.. persimilis } & Control & 11.56 & 0.116 \\
\cline { 2 - 4 } & Ethion & 8.46 & 0.093 \\
\cline { 2 - 4 } & Fenpyroximate & 7.42 & 0.086 \\
\cline { 2 - 4 } & Etoxazole & 6.16 & 0.080 \\
\cline { 2 - 4 } & Chlorfenapyr & 3.22 & 0.077 \\
\cline { 2 - 4 } & Abamectin & 3.48 & 0.074 \\
\hline
\end{tabular}

Table (6) Survival percentages of $T$. urticae and P. persimilis immature and adult females after egg treatment with acaricides at $28 \pm 2{ }^{\circ} \mathrm{C}$.

\begin{tabular}{|c|c|c|c|c|c|}
\hline \multirow{2}{*}{ Species } & \multirow{2}{*}{ Treatment } & \multicolumn{3}{|c|}{ Survival of immature stages $\%$} & \multirow[b]{2}{*}{ Mean of adult mergence } \\
\hline & & Larva & Protonymph & Deutonymph & \\
\hline \multirow{6}{*}{ T. urticae } & Control & 100.0 & 100.0 & 100.0 & 100.0 \\
\hline & Ethion & 100.0 & 80.0 & 85.0 & 88.3 \\
\hline & Fenpyroximate & 95.0 & 80.0 & 70.0 & 81.0 \\
\hline & Etoxazole & 90.0 & 100.0 & 50.0 & 80.0 \\
\hline & Chlorfenapyr & 85.0 & 40.0 & 50.0 & 58.3 \\
\hline & Abamectin & 50.0 & 70.0 & 50.0 & 56.7 \\
\hline \multirow{6}{*}{$\begin{array}{c}P . \\
\text { persimilis }\end{array}$} & Control & 100.0 & 100.0 & 100.0 & 100.0 \\
\hline & Ethion & 95.0 & 98.0 & 80.0 & 91.0 \\
\hline & Fenpyroximate & 90.0 & 88.0 & 80.0 & 86.0 \\
\hline & Etoxazole & 85.0 & 75.5 & 70.0 & 76.7 \\
\hline & Chlorfenapyr & 50.0 & 40.0 & 35.0 & 41.6 \\
\hline & Abamectin & 45.0 & 45.0 & 50,0 & 46.7 \\
\hline
\end{tabular}

except treating egg with Fenpyroximate and the control being $17.21,18.59,12.45,12.92$ and 16.93 days after treating eggs with the five tested acaricides; respectively, while it was 20.75 days in the control.

\section{Growth index (GI) and developmental rate (DR):}

Table (5), showed that Growth index of T. urticae female recorded 7.51, 7.04, 7.49, 7.00 and 4.54 when eggs were treated with Ethion, Fenpyroximate , Etoxazole , Chlorfenapyr and Abamectin; while it was 10.05 in the control . Meanwhile, GI was 8.46, 7.42, 6.16, 3.22 and 3.48 for $P$. parsimilis female after treating eggs with the aforementioned acaricides; while it was 11.56 in the control. Developmental rates of $T$. urticae female recorded $0.085,0.087,0.094,0.120$ and 0.080 after treated eggs with the five acaricides; respectively, compared with 0.101 in the control. Meanwhile, DR was $0.093,0.086,0.080,0.077$ and 0.074 of $P$. persimilis, and it was 0.116 in the control.

\section{Survival percentage:}

Table (6) showed that, Abamectin was the most effective acaricide on the mean survival of immature stages of T. urticae, $56.70 \%$, followed by Chlorfenapyr, Etoxazole, Fenpyroximate and Ethion; they recorded 58.3, 80.0, 81.0 and $88.3 \%$ of control, respectively. Chlorfenapyr was the most effective acaricide on the mean survival percentage of $P$. persimilis immature, it caused $41.6 \%$ of the control followed by Abamectin, Etoxazole, Fenpyroximate and Ethion, recorded 46.7, 76.7, 86.0 and $91.0 \%$ of the control; respectively. Abd El-Mageed et al. (2012) reported that ethion, chlorfenapyr and etoxazole were much less toxic to $P$. persimilis adult females than those of $T$. urticae. Kim \& Yoo (2002) reported that survival after 
treatment with etoxazole was $86 \%$ and $66 \%$ for $P$. persimilis and T. urticae adult females; respectively.

\section{REFERENCES}

Abd El- Mageed, A. E. M.; Tawfik, A. A. and Abohatab,E. E. 2012. Assessment of bioassay techniques and residual effect of certain acaricides against two spotted spider mite,

Tetranychus urticae Koch and its natural enemy, Phytoseiulus persimilis Athias-Henriot . Plant Protection Science. In press.

Carlo, D.; Valeria, M.; Marisa, C.; Marialivia, L. and Sauro, S. 2008. Comparative toxicity of botanical and reduced-risk insecticides to Mediterrenanean populations of Tetranychus urticae and Phytoseiulus persimilis (Acari, Tetranychidae, Phytoseiidae). Bio. Cont., 47:16- 21.

Castagnoli, M.; Liguori, M.; Simoni, S.and Duso, C. 2005. Toxicity of some insecticides to Tetranychus urticae, Neoseiulus californicus and Tydeus californicus. Bio.Control, 50: 611-622.

CoHort Software 2004. CoStat. www. cohort. com. Monterey, California, USA.

Duso, C.; Malagnini, V.; Pozzebon, A.; Castagnli, M.; Liguori, M. and Simoni, S. 2008 .Comparative toxicity of botanical and reducedrisk insecticides to Mediterranean populations of Tetranychus urticae and Phytoseiulus persimilis (Acari Tetranychidae, Phytoseiidae). Bio. Control, 47: 16-21.

Helle,W. and Sabelis, M.W.1985. Spider mites:their biology, natural enemies and control, Vol. 1B . Elsevier, Amsterdam.
Ingeborg K., and Karin W. 2007. The effect of pesticides used in strawberries on the phytophagous mite Tetranychus urticae (Acari Tetranychidae) and its fungal natural enemy Neozygites Floridana (Zygomycetes: Entomophthorales) Biol. Control., 43: $222-230$.

Kims,S., Yoo, S.S. 2002. Comparative toxicity of some acaricides to the predatory mite, Phytoseiulus persimilis and the two spotted spider mite, Tetranychus urticae. Bio. Cont. ,47: 563-573.

Lee, S. G.;Hilton, S. A.; Broadbent, A. B. and Kim, J. H. 2002. Insecticide resistance in phytoseiid predatory mites, Phytoseiulus persimilis and Amblyseius cucumeris (Acarina: Phytoseiidae). J. of Asia Pacific Entomology, 5: 123-129.

Malezieux, S.; Lapchin, L.;Pralavorio, M.; Moulin J. C. and Fournier, D. 1992. Toxicity of pesticide residues to a beneficial arthropod, Phytoseiulus persimilis (Acari: Phytoseiidae). J. Econ. Entomol., 85: 2077-2081.

Omkar, S. S. and James, B. E. 2004. Influence of temperature on the survival, development of immature stages and reproduction of aladybeetle, Coccinella transversalis Fabricius. Entomol. India ,29(1): 13-23.

Saenz-de-Cabezon Irigaray, F. J.; Zalom, F. G. and Thompson, P. B. 2007. Residual toxicity of acaricides to Galendromus occidentalis and Phytoseiulus Persimilis reproductive potential. Bio. Control, 40: 153-159.

Van de Vrie, M.; McMurtry, J. A. and Huffaker, C. B. 1972. III. Biology, ecology, and pest status, and host-plant relations of tetranychids. Hilgardia, 41:343-4. 